\title{
ANALISIS PERSEPSI KONSUMEN TERHADAP MINAT BELI ONLINE
}

\author{
Elinda Haryanto \\ Program Studi Magister Manajemen Universitas Tarumanagara \\ elindaharyanto@gmail.com
}

Masuk : 07-12-2020, revisi : 21-12-2020, diterima untuk diterbitkan :22-12-2020

\begin{abstract}
The purpose of this research is to analyze the effect of consumer perceptions on web design, consumer perceptions of ease of use, consumer perceptions of trust, consumer perceptions of security, consumer perceptions of customer service, consumer perceptions of electronic word of mouth on purchase intention so that it can help online businesses to increase their income and performance. The total sample was 115 respondents, the majority of whom were 30-40 years old. Data analysis used the SPSS version 25 program. The results showed that there was a positive and significant influence respectively between consumer perceptions of trust, consumer perceptions of security, consumer perceptions of customer service, and consumer perceptions of electronic word of mouth on purchase intention. However, for the variable, the influence of consumer perceptions of web design and consumer perceptions of ease of use on purchase intention, the results are not significant. Online business players are advised to prioritize main attention to aspects of consumer perceptions of trust and security, then continue with consumer perceptions of electronic word of mouth and customer service which overall will influence online purchase intention.
\end{abstract}

Keywords: Consumer Perceptions, Web Design, Ease of Use, Trust, Security, Customer Service, Electronic Word of Mouth, Purchase Intention

Abstrak: Tujuan penelitian ini adalah untuk menganalisis pengaruh persepsi konsumen atas web design, persepsi konsumen atas kemudahan penggunaan, persepsi konsumen atas kepercayaan, persepsi konsumen atas keamanan, persepsi konsumen atas layanan pelanggan, persepsi konsumen atas electronic word of mouth terhadap minat beli secara online, sehingga bisa membantu para pelaku bisnis online untuk lebih meningkatkan pendapatan dan kinerjanya. Total sampel sebanyak 115 responden yang mayoritas berusia 30-40 tahun. Analisis data menggunakan program SPSS versi 25. Hasil penelitian menunjukkan bahwa terdapat pengaruh yang positif dan signifikan masing-masing antara persepsi konsumen atas kepercayaan, persepsi konsumen atas keamanan, persepsi konsumen atas layanan pelanggan dan persepsi konsumen atas electronic word of mouth terhadap minat beli secara online. Namun, untuk variabel pengaruh persepsi konsumen atas web design dan persepsi konsumen atas kemudahan penggunaan terhadap minat beli secara online hasilnya adalah tidak signifikan. Pelaku bisnis online disarankan memprioritaskan perhatian utama terhadap aspek persepsi konsumen atas kepercayaan dan keamanan kemudian dilanjutkan dengan persepsi konsumen atas electronic word of mouth dan layanan pelanggan yang secara keseluruhan akan mempengaruhi minat beli secara online.

Kata Kunci: Persepsi Konsumen, Web Design, Kemudahan Penggunaan, Kepercayaan, Keamanan, Layanan Pelanggan, Electronic Word of Mouth, Minat Beli

\section{PENDAHULUAN}

Lebih dari 150 juta masyarakat Indonesia atau sekitar $64.8 \%$ dari total proyeksi tahun 2019 sebanyak 264 juta jiwa penduduk Indonesia (Badan Litbang, 2019) sudah terhubung ke Internet. Internet mampu menambah pendapatan seseorang dalam perekonomian dan mampu memenuhi keinginan masyarakat dalam berbelanja secara praktis yaitu pada toko online yang bisa dilakukan melalui website atau situs belanja online, sosial media dan aplikasi belanja 
online. Hal ini mendukung mengapa fenomena belanja online makin dinikmati di kalangan masyarakat Indonesia. Jumlah konsumen digital saat ini telah tumbuh menjadi 137 juta (Jatmiko, 2020), diperkirakan terus mengalami peningkatan setiap tahunnya. Globalisasi, teknologi dan konektivitas internet telah meningkatkan belanja online, yang telah menjadi tren konsumen secara global dalam beberapa dekade terakhir (Pappas et al., 2014).

Walaupun belanja online makin populer, masalah beragam persepsi yang akan membentuk minat beli konsumen dalam belanja online masih menjadi isu penting yang sering ditemukan seperti masalah penipuan atau penjualan fiktif dan kecewa terhadap kualitas produk yang dibelinya, masih ada sebagian kalangan yang masih tidak mau mengikuti tren dalam rantai ekonomi berbasis digital tersebut, padahal belanja online menawarkan beberapa kelebihan diantaranya hemat waktu dan praktis, produk yang ditawarkan sangat beragam dan lengkap juga mudah untuk membandingkan harga antar produk serupa, banyak promo diskon maupun cashback. Beberapa persepsi negatif yang timbul ini akan menghilangkan minat beli secara online. Sesuai dengan pendapat (Nasution et al., 2019) bahwa untuk mengubah persepsi negatif tentang belanja online dan meningkatkan penjualan online, maka harus fokus ke beberapa faktor yang mempengaruhi minat beli secara online.

\section{Tujuan Penelitian}

Dari berbagai persepsi konsumen yang muncul, guna tetap mempertahankan dan tidak menghilangkan kesempatan perolehan penjualan pada toko online, maka tujuan penelitian ini adalah untuk menganalisis seberapa besar pengaruh persepsi konsumen atas web design, persepsi konsumen atas kemudahan penggunaan, persepsi konsumen atas kepercayaan, persepsi konsumen atas keamanan, persepsi konsumen atas layanan pelanggan, persepsi konsumen atas electronic word of mouth terhadap minat beli secara online.

\section{TINJAUAN PUSTAKA}

Teori Adopsi (Adoption theory) bertujuan untuk menjelaskan faktor penting yang mendorong orang untuk melakukan perilaku tertentu, mulai dari proses menerima produk baru, mode baru atau ide baru oleh konsumen. Teori tindakan beralasan (theory of reasoned action) adalah model pertama dari teori adopsi yang awalnya dikemukakan oleh Fishbein dan Ajzen pada tahun 1975. Model ini bertumpu pada asumsi yang mendasari bahwa prediktor terbaik dari perilaku individu adalah niat, yang sangat ditentukan oleh sikap terhadap kinerja dan norma subjektif yang terkait dengan suatu perilaku (Dang \& Pham, 2018, p. 954). Model teori perilaku terencana menunjukkan bahwa persepsi individu tentang kontrol, sikap terhadap perilaku dan norma subjektif merupakan faktor-faktor yang mempengaruhi niat untuk menunjukkan perilaku tertentu ((Dang \& Pham, 2018, p. 954).

Model penerimaan teknologi (Technology Acceptance Model) adalah sebuah aplikasi pengembangan dari Teori tindakan beralasan (Theory of reasoned action). Menurut Davis (1989), teori ini adalah sebuah teori sistem informasi yang dirancang guna menerangkan bagaimana pengguna mengerti dan mengaplikasikan sebuah teknologi informasi. Struktur asli teori ini yang dirumuskan oleh Davis (1989), adalah persepsi kegunaan, persepsi kemudahan pemakaian, sikap, niat perilaku, pemakaian sebenarnya dan ditambahkan beberapa faktor eksternal seperti, pengalaman dan kerumitan.

Kotler dan Keller (2009, p. 179) mengartikan persepsi sebagai proses dimana kita memilih, mengatur dan menerjemahkan masukan informasi untuk menciptakan gambaran dunia yang berarti. Perilaku aktual konsumen dipengaruhi oleh persepsi dalam pemasaran dan persepsi lebih penting daripada realitas. Persepsi orang bisa berbeda mengenai objek yang sama karena adanya tiga proses pemahaman seperti atensi selektif, distorsi selektif dan retensi selektif. Persepsi web design menurut (Shahnaz \& Wahyono, 2016, p. 392) adalah tempat dimana konsumen dapat memperoleh informasi dengan mudah, baik informasi mengenai produk atau jasa sesuai dengan kebutuhan. Konsep kemudahan penggunaan menjelaskan bahwa teknologi tersebut dapat dengan mudah dipahami tanpa memerlukan usaha kerasa oleh 
pengguna (Andryanto, 2016, p. 26). Menurut Firdayanti (2012, p. 2), kepercayaan konsumen adalah persepsi dari sudut pandang konsumen akan keandalan penjual dalam pengalaman dan terpenuhinya harapan dan kepuasan konsumen. Keamanan merupakan hal yang mampu memberikan pengaruh kepada konsumen, karena jaminan keamanan dan kerahasiaan data merupakan hal yang penting ketika berbelanja secara online (Rafidah, 2017, p. 15). Elemenelemen layanan pelanggan yang penting bagi pedagang online termasuk efisiensi layanan, daya tanggap, fleksibilitas, jaminan, interaksi, dukungan, informasi dan personalisasi (Yang \& Fang, 2004). Online word of mouth adalah sumber daya penting bagi pelanggan dan pembeli potensial untuk menyampaikan pengalaman menggunakan barang tersebut (Tanimoto \& Fujii, 2003). Minat beli menurut Kotler (2005, p. 205) adalah sesuatu yang muncul setelah melihat produk lalu menerima rangsangan, kemudian tertarik untuk mencoba produk tersebut sampai pada akhirnya timbul keinginan untuk membeli agar dapat memilikinya. Setelah persepsi timbul dan memberikan pengaruh terhadap perilaku konsumen, maka artinya konsumen sudah mempunyai keinginan dan ingin terlibat ke dalam transaksi secara online (minat beli).

\section{METODOLOGI PENELITIAN}

Metode kuantitatif dengan pendekatan deskriptif digunakan dalam penelitian ini. Populasi yang digunakan dalam penelitian ini adalah pengguna internet yang pernah mengunjungi atau berbelanja secara online. Penelitian ini menggunakan desain non-probability sampling dengan cara convenience sampling yaitu kumpulan informasi-informasi dari anggotaanggota populasi yang dengan setuju mau memberikan informasi tersebut (Sekaran \& Bougie, 2017, p. 121). Jumlah responden terpilih dan memenuhi kriteria sebanyak 115 orang.

Sumber data yang digunakan dalam penelitian ini adalah data primer dan menggunakan metode pengumpulan data berupa kuesioner yang akan disebarkan melalui online google form. Pengolahan data akan menggunakan bantuan program SPSS versi 25.

\section{HASIL DAN KESIMPULAN}

Penelitian ini menghasilkan persamaan regresi linier berganda seperti dibawah ini: $\mathrm{Y}=2,214+0,005 \mathrm{X} 1+0,082 \mathrm{X} 2+1,212 \mathrm{X} 3+0,965 \mathrm{X} 4+0,389 \mathrm{X} 5+0,213 \mathrm{X} 6+\mathrm{e}$

Pengujian Koefisien Regresi Parsial (Uji t) digunakan untuk mengetahui apakah variabel independen berpengaruh secara parsial terhadap variabel dependen.

\section{Tabel 1}

\section{Hasil Uji t, Uji $\mathbf{R}^{2}$ dan Uji f}

\begin{tabular}{|c|c|c|c|}
\hline Model & $\begin{array}{c}\text { Unstandardized } \\
\text { Coefficients }\end{array}$ & $\mathrm{T}$ & Sig \\
\hline Constant & 2,214 & 1,924 & 0,057 \\
\hline Persepsi konsumen atas Web Design (X1) & 0,005 & 0,058 & 0,953 \\
\hline Persepsi konsumen atas Kemudahan Penggunaan (X2) & 0,082 & 1,147 & 0,254 \\
\hline Persepsi konsumen atas Kepercayaan (X3) & 1,212 & 6,201 & 0,000 \\
\hline Persepsi konsumen atas Keamanan $(X 4)$ & 0,965 & 5,333 & 0,000 \\
\hline Persepsi konsumen atas Layanan Pelanggan (X5) & 0,389 & 2,036 & 0,044 \\
\hline Persepsi konsumen atas electronic word of mouth (X6) & 0,213 & 3,447 & 0,001 \\
\hline $\mathrm{F}$ & 50,567 & & 0,000 \\
\hline $\mathrm{R}^{2}$ & 0,737 & & \\
\hline
\end{tabular}

Berdasarkan tabel diatas, dapat dilihat bahwa variabel pengaruh persepsi konsumen atas web design terhadap minat beli secara online adalah tidak signifikan dengan nilai signifikansi sebesar 0,953 (lebih besar dari 0,05) dan nilai $\mathrm{T}$ hitung sebesar 0,058 (lebih kecil dari $\mathrm{T}$ tabel 1,98). Hal ini sesuai dengan penelitian yang dilakukan oleh Shahnaz dan Wahyono (2016), namun berbeda dengan penelitian yang dilakukan oleh Dang dan Pham (2018) dan Gudigantala et al., (2016) yang menyimpulkan bahwa persepsi atas web design secara signifikan dan positif berpengaruh terhadap minat beli. Perbedaan hasil penelitian ini dengan penelitian-penelitian terdahulu disebabkan karena pola perilaku masyarakat Indonesia yang cenderung lebih 
mengutamakan kredibilitas platform belanja online, keseluruhan servis yang disediakan, selalu membaca review online dan faktor lainnya seperti promo, diskon, cashback atau gratis biaya kirim membuat persepsi atas tampilan web design tidak menjadi persepsi utama yang dikhawatirkan untuk mendorong minat pembelian secara signifikan.

Hasil penelitian ini juga menunjukkan bahwa variabel pengaruh persepsi konsumen atas kemudahan penggunaan terhadap minat beli secara online adalah tidak signifikan dengan nilai signifikansi sebesar 0,254 (lebih besar dari 0,05) dan nilai T hitung sebesar 1,147 (lebih kecil dari $\mathrm{T}$ tabel 1,98). Hal ini sesuai dengan penelitian yang dilakukan oleh Khotimah dan Febriansyah (2018), namun berbeda dengan hasil penelitian dari Nasution et al., (2019), Phongsath dan Jirawoottirote (2018) dan Moslehpour et al., (2018). Mengacu pada hasil deskriptif, mayoritas responden memiliki ijazah perguruan tinggi dari sisi level pendidikan dimana mereka sudah mampu melakukan navigasi sendiri pada saat masuk ke platform belanja online tanpa perlu bimbingan lebih lanjut dari orang lain sehingga persepsi atas kemudahan penggunaan bukan menjadi yang utama dan tidak dapat mempengaruhi minat beli secara signifikan.

Hipotesis selanjutnya menujukkan bahwa terdapat pengaruh yang positif dan signifikan masing-masing antara persepsi konsumen atas kepercayaan (Cho \& Sagynov, 2015; Ozdemir \& Sonmezay, 2020; Shahnaz \& Wahyono, 2016), persepsi konsumen atas keamanan (Alwafi \& Magnadi, 2016; Anwar \& Afifah, 2018), persepsi konsumen atas layanan pelanggan (Bakti et al., 2020; Dang \& Pham, 2018; Kalia et al., 2016; Permana, 2020) dan persepsi konsumen atas electronic word of mouth (Arafah et al., 2019; Lee et al., 2017; Nasution et al., 2019; Nuseir, 2019) terhadap minat beli secara online dengan nilai signifikansi masing-masing variabel lebih kecil dari 0,05 dan nilai T hitung lebih besar dari 1,98 berdasarkan Tabel 1. Dapat disimpulkan bahwa ketika pelaku bisnis online dapat memenuhi semua kewajibannya termasuk memberikan kualitas layanan baik dan berkualitas sehingga ekspektasi konsumen terpenuhi dan rasa aman yang diterima konsumen, maka semua persepsi ini berpengaruh terhadap minat beli secara online. Minat beli juga akan dipengaruhi persepsi komentar online dari konsumen lainnya, konsumen juga akan membaca, merujuk dan percaya komentar tersebut sebelum melakukan pembelian.

Nilai Adjusted R Square pada tabel diatas menunjukkan nilai 0,723 yang artinya sebesar 72,3\% variabel dependen yaitu minat beli dapat dijelaskan oleh enam variabel independen (persepsi konsumen atas web design, kemudahan penggunaan, kepercayaan, keamanan, layanan pelanggan dan electronic word of mouth), sedangkan sisanya $27,7 \%$ dijelaskan oleh faktor-faktor lain selain enam variabel independen tersebut.

Nilai Fhitung adalah 50,567 dan nilai Signifikan sebesar 0,000, dapat disimpulkan bahwa Fhitung lebih besar dari Ftabel yaitu 50,567 lebih besar dari 2,18 berarti hipotesis diterima. Nilai signifikan lebih kecil dari 0,05 berarti variabel persepsi konsumen atas web design, kemudahan penggunaan, kepercayaan, keamanan, layanan pelanggan dan electronic word of mouth secara simultan atau bersama-sama berpengaruh positif atau signifikan terhadap variabel minat beli.

\section{SARAN}

Bagi para pelaku bisnis online, harus menerapkan prinsip kejujuran dengan memastikan produk yang dijual secara online sesuai dengan kenyataan, kelengkapan informasi yang diberikan kepada konsumen juga benar, serta pengiriman produk tepat waktu. Juga para pelaku bisnis harus memberikan kemudahan komunikasi bagi konsumen dengan cara selalu memberikan respon yang tepat dan cepat dan pelayanan terbaik termasuk menanggapi jika ada komentar online yang negatif. Terakhir para pelaku bisnis online harus tetap konsisten mempertahankan persepsi konsumen atas kepercayaan, keamanan, layanan pelanggan dan electronic word of mouth agar meningkatan pendapatan penjualan. 
Bagi para peneliti selanjutnya diharapkan dapat spesifik memilih pelaku bisnis online tertentu yang perlu diuji, menggunakan disain sampel probability sampling dan memilih sampel sistematis atau sampel stratifikasi, termasuk memperbanyak jumlah sampel, menambah pernyataan dari setiap item atau indikator yang diajukan pada kuesioner dan variabel independen lainnya sehingga seluruh faktor yang mempengaruhi minat beli secara online dapat tertangkap seluruhnya.

\section{DAFTAR PUSTAKA}

Alwafi, F., \& Magnadi, R. H. (2016). Pengaruh persepsi keamanan, kemudahan bertransaksi, kepercayaan terhadap toko dan pengalaman berbelanja terhadap minat beli secara online pada situs jual beli Tokopedia.com. Diponegoro Journal of Management, 5(2), 1-15. https://ejournal3.undip.ac.id/index.php/djom/article/view/13857/13407

Andryanto, R. (2016). Pengaruh kepercayaan, persepsi manfaat dan persepsi kemudahan penggunaan terhadap minat beli di toko online (Studi empiris yang dilakukan pada OLX.co.id di Yogyakarta) [Universitas Negeri Yogyakarta]. https://eprints.uny.ac.id/41480/1/RezaAndryanto_12808144073.pdf

Anwar, R. N., \& Afifah, A. (2018). Kepercayaan dan keamanan konsumen terhadap minat beli di situs online (Studi kasus pengunjung situs Lazada di Jakarta Timur). Jurnal Manajemen, 9(1), 46-57. https://doi.org/10.32832/jm-uika.v9i1.1316

Arafah, W., Lukito, N., \& Rikang, R. (2019). Antecedents from purchase intention of retail brand "X": Evidence from Indonesia. Academy of Marketing Studies Journal, 23(4), 114. https://elibrary.jcu.edu.au/login?url=https://www.proquest.com/scholarlyjournals/antecedents-purchase-intention-retail-brand-x/docview/2424514687/se2? accountid=16285\%0Ahttps://jcu.primo.exlibrisgroup.com/openurl/61ARL_JCU/61A RL_JCU:JCU??url_ver=Z39.88-2

Badan Litbang. (2019). APJII: Jumlah pengguna internet di Indonesia tembus 171 juta jiwa. https://litbang.kemendagri.go.id/website/apjii-jumlah-pengguna-internet-di-indonesiatembus-171-juta-jiwa/

Bakti, U., Hairudin, \& Alie, M. S. (2020). Pengaruh kualitas pelayanan, produk dan harga terhadap minat beli pada toko online Lazada di Bandar Lampung. Jurnal Ekonomi, 22(1), 101-118. https://mediakonsumen.com/2018/05/14/sur

Cho, Y. C., \& Sagynov, E. (2015). Exploring factors that affect usefulness, ease of use, trust, and purchase intention in the online environment. International Journal of Management \& Information Systems (IJMIS), 19(1), 21-36. https://doi.org/10.19030/ijmis.v19i1.9086

Dang, V. T., \& Pham, T. L. (2018). An empirical investigation of consumer perceptions of online shopping in an emerging economy: Adoption theory perspective. Asia Pacific Journal of Marketing and Logistics, 30(4), 952-971. https://doi.org/10.1108/APJML01-2018-0038

Davis, F. D. (1989). Perceived usefulness, perceived ease of use, and user acceptance of information technology. MIS Quarterly: Management Information Systems, 13(3), 319339. https://doi.org/10.2307/249008

Firdayanti, R. (2012). Persepsi risiko melakukan e-commerce dengan kepercayaan konsumen dalam membeli produk fashion online. Journal of Social and Industrial Psychology, 1(1), 1-7. https://journal.unnes.ac.id/sju/index.php/sip/article/view/2660

Gudigantala, N., Bicen, P., \& Eom, M. (Tae in). (2016). An examination of antecedents of conversion rates of e-commerce retailers. Management Research Review, 39(1), 82-114. https://doi.org/10.1108/MRR-05-2014-0112

Jatmiko, L. D. (2020). Tahun ini, Indonesia punya 137 juta konsumen digital. Bisnis.Com. https://teknologi.bisnis.com/read/20200831/266/1285199/tahun-ini-indonesia-punya137-juta-konsumen-digital 
Kalia, P., Arora, R., \& Kumalo, S. (2016). E-service quality, consumer satisfaction and future purchase intentions in e-retail. E-Service Journal, 10(1), 24.

https://doi.org/10.2979/eservicej.10.1.02

Khotimah, K., \& Febriansyah. (2018). Pengaruh kemudahan penggunaan, kepercayaan konsumen dan kreativitas iklan terhadap minat beli konsumen online-shop. Jurnal Manajemen Strategi Dan Aplikasi Bisnis, 1(1), 19-26. https://doi.org/10.36407/jmsab.v1i1.16

Kotler, P. (2005). Manajemen pemasaran. PT Indeks Kelompok Gramedia.

Kotler, P., \& Keller, K. L. (2009). Manajemen pemasaran (1st ed.). Erlangga.

Lee, W. I., Cheng, S. Y., \& Shih, Y. T. (2017). Effects among product attributes, involvement, word-of-mouth, and purchase intention in online shopping. Asia Pacific Management Review, 22(4), 223-229. https://doi.org/10.1016/j.apmrv.2017.07.007

Moslehpour, M., Pham, V. K., Wong, W. K., \& Bilgiçli, I. (2018). e-Purchase intention of Taiwanese consumers: Sustainable mediation of perceived usefulness and perceived ease of use. Sustainability (Switzerland), 10(1), 10-17. https://doi.org/10.3390/su10010234

Nasution, M. D. T. P., Rossanty, Y., Ariffin, K. H. K., \& Zaini, N. I. B. M. (2019). An empirical examination of the factors influencing consumer's purchase intention toward online shopping. Journal of Business \& Retail Management Research, 13(04), 14-29. https://doi.org/10.24052/jbrmr/v13is04/art-02

Nuseir, M. T. (2019). The impact of electronic word of mouth (e-WOM) on the online purchase intention of consumers in the Islamic countries - a case of (UAE). Journal of Islamic Marketing, 10(3), 759-767. https://doi.org/10.1108/JIMA-03-2018-0059

Ozdemir, E., \& Sonmezay, M. (2020). The effect of the e-commerce companies benevolence, integrity and competence characteristics on consumers perceived trust, purchase intention and attitudinal loyalty. Business and Economics Research Journal, 11(3), 807821. https://doi.org/10.20409/berj.2020.283

Pappas, I. O., Pateli, A. G., Giannakos, M. N., \& Chrissikopoulos, V. (2014). Moderating effects of online shopping experience on customer satisfaction and repurchase intentions. International Journal of Retail and Distribution Management, 42(3), 187204. https://doi.org/10.1108/IJRDM-03-2012-0034

Permana, A. I. (2020). Pengaruh kualitas website, kualitas pelayanan, dan kepercayaan pelanggan terhadap minat beli pelanggan di situs belanja online Bukalapak. Ekonomi Bisnis, 25(2), 94-109. https://doi.org/10.33592/jeb.v25i2.422

Phongsath, T., \& Jirawoottirote, V. (2018). Factors influencing online purchase intention. $A U$ E-Journal of Interdisciplinary Research, 3(2), 249-258. http://www.assumptionjournal.au.edu/index.php/eJIR/article/view/4182/2471

Rafidah, I. (2017). Analisis keamanan, kemudahan, dan kepercayaan terhadap keputusan pembelian secara online di Lazada. Jurnal Ilmu Dan Riset Manajemen, 6(2), 1-17. http://jurnalmahasiswa.stiesia.ac.id/index.php/jirm/article/view/726/736

Sekaran, U., \& Bougie, R. (2017). Metode penelitian untuk bisnis (6th ed.). Salemba Empat.

Shahnaz, N. B. F., \& Wahyono. (2016). Faktor yang mempengaruhi minat beli konsumen di toko online. Management Analysis Journal, 5(4), 389-399.

https://doi.org/10.15294/maj.v5i4.5571

Tanimoto, J., \& Fujii, H. (2003). A study on diffusional characteristics of information on a human network analyzed by a multi-agent simulator. Social Science Journal, 40(3), 479-485. https://doi.org/10.1016/S0362-3319(03)00045-4

Yang, Z., \& Fang, X. (2004). Online service quality dimensions and their relationships with satisfaction: A content analysis of customer reviews of securities brokerage services. International Journal of Service Industry Management, 15(3), 302-326. https://doi.org/10.1108/09564230410540953 